\title{
Bevacizumab Treatment of Radiation-Induced Brain Necrosis: A Systematic Review
}

\author{
Guixiang Liao ${ }^{\text {*t }}$, Muhammad Khan ${ }^{1,2 \dagger}$, Zhihong Zhao ${ }^{3 \dagger}$, Sumbal Arooj ${ }^{4}$, Maosheng Yan ${ }^{\text {* }}$ \\ and Xianming $L i^{1}$
}

${ }^{1}$ Department of Radiation Oncology, Shenzhen People's Hospital, The First Affiliated Hospital of Southern University of Science and Technology, Shenzhen, China, ${ }^{2}$ Department of Oncology, First Affiliated Hospital of Anhui Medical University, Hefei, China, ${ }^{3}$ Department of Nephrology, Shenzhen People's Hospital, Second Clinical Medicine Centre, Jinan University, Shenzhen, China, ${ }^{4}$ Department of Biochemistry, University of Sialkot, Sialkot, Pakistan

OPEN ACCESS

Edited by:

John Varlotto,

Marshall University, United States

Reviewed by:

Hongqing Zhuang,

Peking University Third Hospital, China Young Kwok,

University of Maryland Medical Center, United States

*Correspondence: Guixiang Liao liaoguixiang@163.com Maosheng Yan

maosheng@szhopital.com

${ }^{\dagger}$ These authors have contributed equally to this work

Specialty section: This article was submitted to Radiation Oncology, a section of the journal Frontiers in Oncology

Received: 10 August 2020 Accepted: 09 March 2021 Published: 25 March 2021

Citation:

Liao G, Khan M, Zhao Z, Arooj S, Yan $M$ and Li X (2021) Bevacizumab Treatment of Radiation-Induced Brain Necrosis: A Systematic Review.

Front. Oncol. 11:593449. doi: 10.3389/fonc.2021.593449
Background: Radiation brain necrosis (RBN) is a serious complication in patients receiving radiotherapy for intracranial disease. Many studies have investigated the efficacy and safety of bevacizumab in patients with RBN. In the present study, we systematically reviewed the medical literature for studies reporting the efficacy and safety of bevacizumab, as well as for studies comparing bevacizumab with corticosteroids.

Materials and Methods: We searched PubMed, Cochrane library, EMBASE, and ClinicalTrials.gov from their inception through 1 March, 2020 for studies that evaluated the efficacy and safety of bevacizumab in patients with RBN. Two investigators independently performed the study selection, data extraction, and data synthesis.

Results: Overall, the present systematic review included 12 studies (eight retrospective, two prospective, and two randomized control trials [RCTs]) involving 236 patients with RBN treated who were treated with bevacizumab. The two RCTs also had control arms comprising patients with RBN who were treated with corticosteroids/placebo $(n=57)$. Radiographic responses were recorded in $84.7 \%$ (200/236) of patients, and radiographic progression was observed in 15.3\% (36/236). Clinical improvement was observed in 91\% $(n=127)$ of responding patients among seven studies ( $n=113)$. All 12 studies reported volume reduction on $\mathrm{T} 1$ gadolinium enhancement MRI (median: 50\%, range: $26 \%-80 \%$ ) and/or T2 FLAIR MRI images (median: 59\%, range: 48\%-74\%). In total, 46 responding patients (34\%) had recurrence. The two RCTs revealed significantly improved radiographic response in patients treated with bevacizumab (Levin et al.: $p=0.0013$; Xu et al.: $p<0.001$ ). Both also showed clinical improvement (Levin et al.: NA; Xu et al.: $p=$ 0.039 ) and significant reduction in edema volume on both $\mathrm{T} 1$ gadolinium enhancement MRI (Levin et al.: $p=0.0058$; Xu et al.: $p=0.027$ ) and T2 FLAIR MRI (Levin et al.: $p=0.0149$; $X u$ et al.: $p<0.001)$. Neurocognitive improvement was significantly better after 2 months of treatment in patients receiving bevacizumab than in those given corticosteroids, as assessed by the MoCA scale $(p=0.028)$. The recurrence rate and side effects of the treatments showed no significant differences. 
Conclusions: Patients with RBN respond to bevacizumab, which can improve clinical outcomes and cognitive function. Bevacizumab appears to be more efficacious than corticosteroid-based treatment. The safety profile was comparable to that of the corticosteroids.

Keywords: bevacizumab (BV), radiation-induced brain necrosis (RBN), dexamethasone, neurocognition, magnetic resonance imaging (MRI), adverse events

\section{INTRODUCTION}

Radiotherapy is widely used to treat intracranial diseases (1, 2). However, patients receiving radiotherapy in the brain often present with a late complication called radiation-induced brain injury (RIBI) (3). RIBI is categorized as acute (days to weeks after irradiation), early delayed (1-6 months after irradiation), or late delayed (> 6 months after irradiation) (4). Advancements in immunotherapy have greatly increased the survival rates of patients with brain disease, as have the combination of radiotherapy with immune checkpoint inhibitors or targeted therapy agents (5). As a result, patients are more at risk of experiencing late delayed brain injury, characterized histopathologically by vascular abnormalities, demyelination, and ultimately white matter necrosis (6). Radiation-induced brain necrosis (RBN) is one of the main limiting toxicities, generally occurring 6 months to several years after treatment (7). Furthermore, combining radiation with targeted/immunotherapeutic agents to treat metastatic brain disease confers an increased risk of RBN that must be weighed against the synergistic effects of the treatment $(8,9)$. Therefore, the diagnosis and treatment of RBN are a crucial element in the management of patients with brain diseases.

The pathogenesis of RBN involves late barrier dysfunction and post-irradiation hypoxia, which leads to upregulation of vascular endothelial growth factor (VEGF) $(10,11)$. More specifically, radiotherapy induces endothelial cell loss through acid sphingomyelinase-dependent apoptosis, causing vasogenic edema, ischemia, and hypoxia. As a result, hypoxia-inducible factor $1 \alpha(H I F 1 \alpha)$ is upregulated, leading to increased VEGF production in astrocytes and endothelial cells, mainly in the white matter around areas of necrosis (10). Increased levels of VEGF in reactive astrocytes around a core of necrotic tissue have also been observed using immunohistochemistry in surgical samples of RBN (11), suggesting that VEGF plays a critical role in the development of RBN, and that targeting VEGF with anti-VEGF antibodies could halt RBN development. For this reason, such treatment has been the main focus of preclinical and clinical research in recent years.

Several studies have assessed the efficacy and safety of bevacizumab, an anti-VEGF antibody, in the treatment of RBN. Most of these were case reports or retrospective studies with very few patients and lacked radiographic/clinical evidence (12-19). In the present study, we systematically reviewed the literature for studies investigating the efficacy and safety of bevacizumab in the treatment of $\mathrm{RBN}$. We also searched for studies that compared bevacizumab with corticosteroids in this regard.

\section{MATERIALS AND METHODS}

\section{Study Registration}

This systematic review complied with the PRISMA statement. The protocol was registered on PROSPERO: CRD42019134033.

\section{Criteria for Considering Studies Study Types}

This systematic review included published studies with retrospective, prospective, or randomized controlled trial research designs and more than five participants. Single-arm studies investigating the efficacy and safety of bevacizumab in the treatment of RBN were included, as were studies with comparative arms comparing bevacizumab to corticosteroids in this regard. Other types of studies, such as case reports, conference presentations, comments, studies with fewer than five participants, and studies lacking radiographic evidence were excluded.

\section{Types of Patients}

All studies involved patients with $\mathrm{RBN}$ who were aged $\geq 18$ years old.

\section{Types of Interventions}

In all studies, bevacizumab was used to treat RBN. In some, its efficacy and safety were compared with those of corticosteroids. Other control interventions included placebo, other pharmacological treatments, hyperbaric oxygen, or laser interstitial thermal therapy.

\section{Outcomes of Interest}

The primary outcomes included clinical improvement, assessed in terms of symptomatic improvement/resolution, increase in Karnofsky performance status (KPS) score, decrease in dexamethasone use, radiographic response, and edema volume changes under T2-weighted FLAIR MRI images or T1-weighted gadolinium $(\mathrm{Gd})$-enhanced MRI images. Secondary outcomes of interest included rates of necrosis recurrence, rates of adverse effects, and cognitive function.

\section{Searching Methods for Eligible Studies}

The following databases were included in the search: PubMed, Cochrane Library, EMBASE, and ClinicalTrials.gov since their 
inception. The latest search was conducted on March 1, 2020. The language was restricted to English. The main search terms were "radiotherapy," "radiation brain necrosis," and "bevacizumab." References from all the identified studies were also examined for any additional relevant randomized control trials (RCTs).

\section{Selection of Studies}

The studies from the initial search were imported into the NoteExpress software; all duplicate references were excluded. The remaining studies underwent title and abstract screening by two independent authors (G.L. and Z.Z.). The studies that met the inclusion criteria were retrieved in full-text form and further screened and evaluated by two independent reviewers for final inclusion. Any disagreement was discussed and resolved by all authors.

\section{Data Extraction}

Data from the included studies were extracted using a pre-piloted and standardized method. The following information was extracted: first author of the study, country location, year of publication, sample sizes for each intervention, details of intervention methods, details of patients in each intervention (age, sex, cancer type, dose, and duration of radiation), and outcomes of interest (response rate, progression disease, volume changes of edema under MRI, cognitive function, and adverse effects). Data were extracted by two independent reviewers. Any dispute was resolved through discussion by all reviewers.

\section{Quality and Risk of Bias Assessment}

A reporting checklist created by the MOOSE group was used to assess the quality of the retrospective studies (20). The risk of bias for RCTs was evaluated using Cochrane tools by a pair of reviewers (G.L. and H.Z.) (21).

\section{RESULTS}

A total of 345 studies were identified in the initial search. After vigilant screening of the titles and abstracts, 25 studies underwent full-text assessment. In accordance with the inclusion criteria, 12 studies (eight retrospective, two prospective, and two RCTs) were selected, including 236 patients who had developed $\mathrm{RBN}$ after undergoing radiotherapy and/or stereotactic radiosurgery (SRS) for the treatment of intracranial disease (22-33). The research strategy and study selection flowchart of this systematic review are presented in Figure 1. The two RCTs also included a

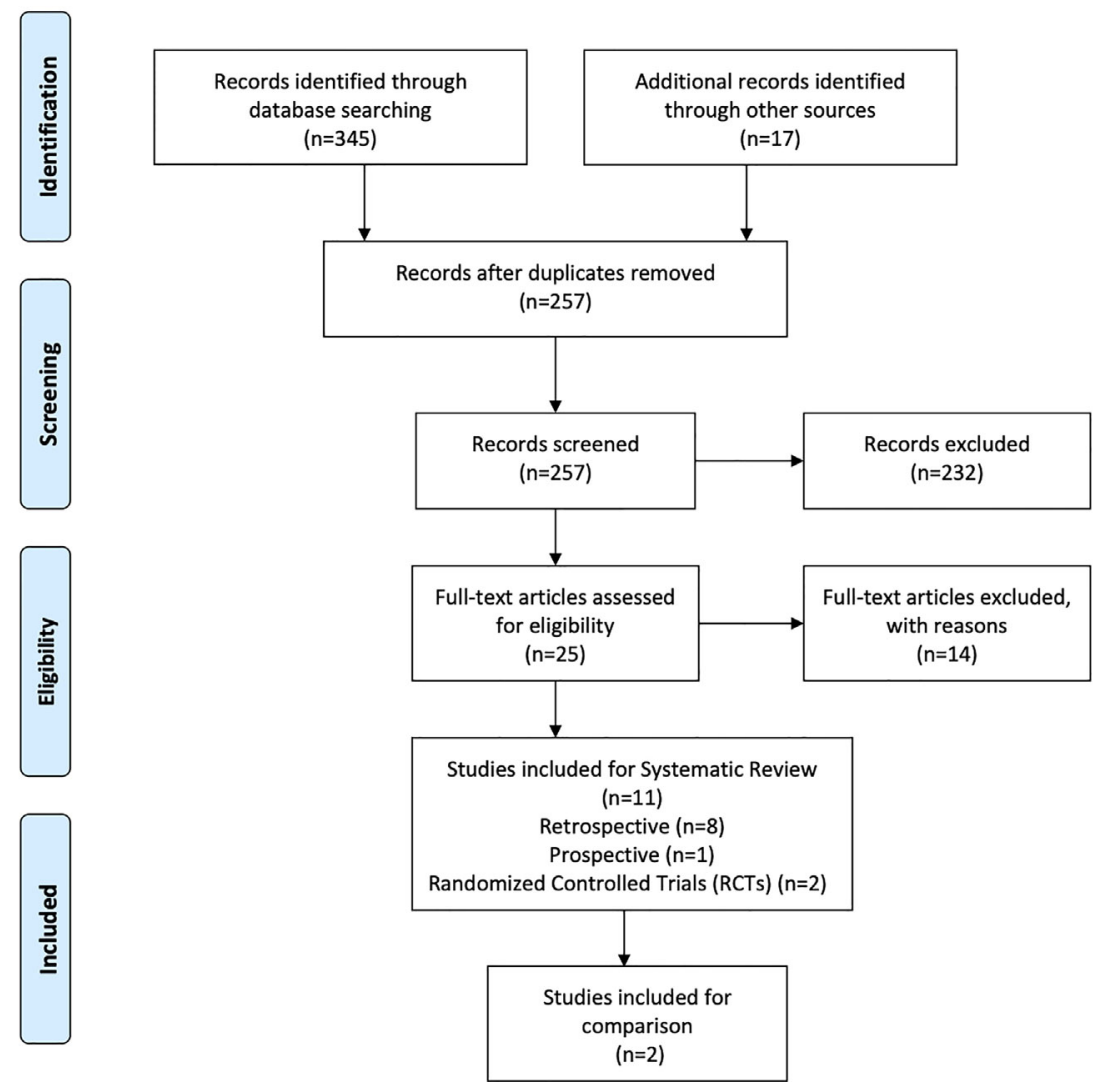

FIGURE 1 | PRISMA flow diagram of research strategy and study selection. 
comparison of bevacizumab with corticosteroid/placebo-based management of RBN $(24,32)$. The risk of bias assessment of these RCTs is shown in Figure 2.

\section{General Characteristics of Studies and Participants}

The 12 studies included 236 patients with RBN who were treated with bevacizumab (22-33). Ninety-five of the participants were women (40\%) and 141 were men (60\%) (22-33). The patients' intracranial diseases included various primary brain tumors, metastatic disease, nasopharyngeal carcinoma (NPC), and benign pathologies such as arteriovenous malformation with different frequencies, as presented in Figure 3. Patients with NPC were only included in two studies, but they comprised the largest disease group in the present study $(\mathrm{n}=108)$, followed by those with brain metastasis (BM; $\mathrm{n}=71$ ) and glioblastoma $(\mathrm{n}=23)(22-33)$. Conventional radiotherapy (external beam radiotherapy, intensity modulated radiotherapy, wholebrain radiotherapy, hypofractionated radiotherapy) and stereotactic radiotherapy were administered to 200 patients $(83.7 \%)$ as the first course of treatment, while 31 patients (14.4\%) received SRS as the first radiotherapy. Overall, 41 patients $(19 \%)$ had undergone a second course/boost of radiation, of which $34(83 \%)$ had received SRS. The diagnosis of RBN was predominantly confirmed by imaging findings on MRI, MRS, and PET scans. Biopsies were also provided in some studies (22-33). The diagnostic methods used in each study are listed in Table 1. The average time from induction of radiotherapy to RBN diagnosis or bevacizumab treatment ranged from 6 months to 38.8 months in patients who had received radiotherapy, and from 6.5 to 10.6 months in those who had undergone SRS. Various doses of bevacizumab were used, ranging from $1 \mathrm{mg} / \mathrm{kg}$ to $15 \mathrm{mg} / \mathrm{kg}$ every $2 / 3 / 4 / 6$ weeks for an average of 2-7 cycles per study. The average follow-up time reported in the studies ranged from 8.1 months to 22.7 months. Detailed information about the characteristics of the studies, participants, and interventions is presented in Table 1. The timeline for overall management of the included patients, along with the main outcome results, is graphically presented in Figure 4.

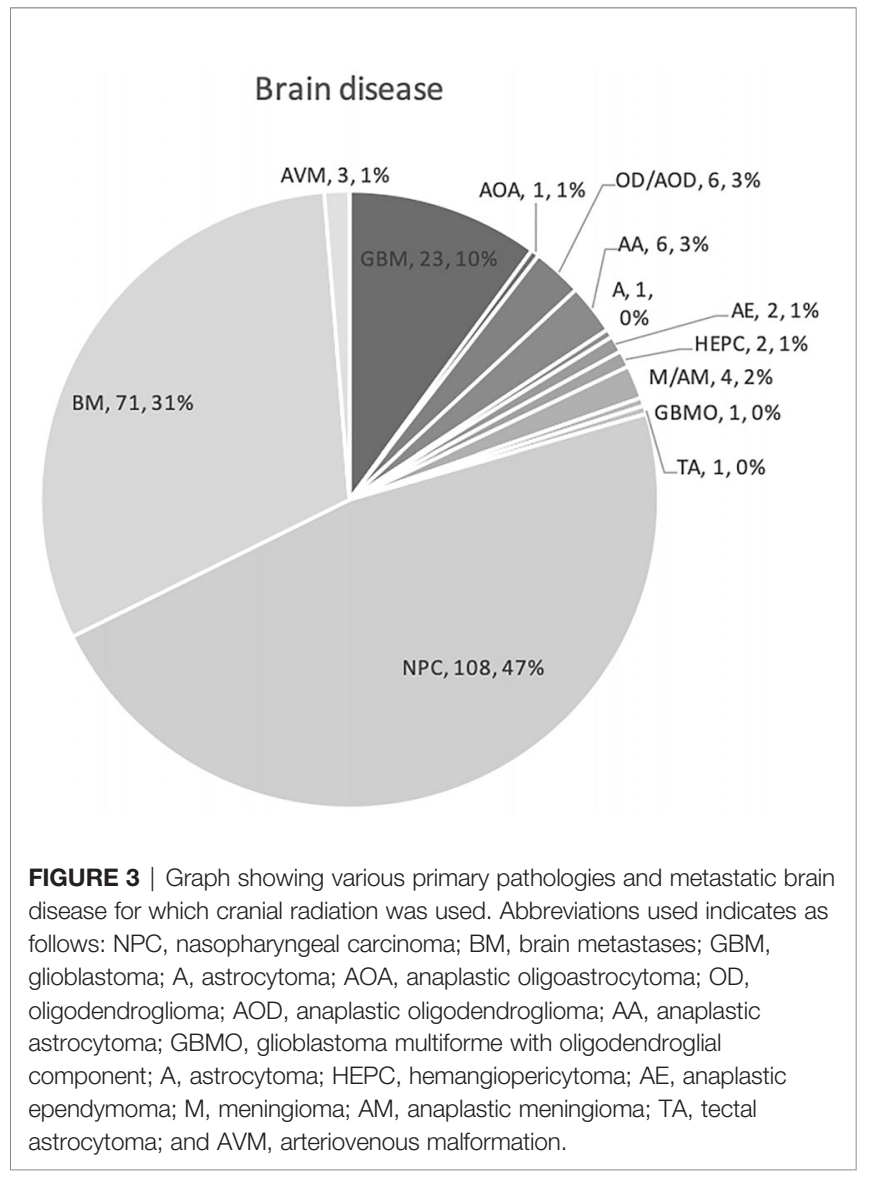

\section{Clinical Improvement}

Clinical improvement was assessed in terms of improvement in neurological symptoms and signs, KPS score, and tapering of dexamethasone dosage.

\section{Improvement in Neurological Symptoms/Signs}

Resolution or improvement in neurological symptoms/signs and clinical outlook was reported in eight studies involving 133 patients who were radiographically responsive $(23-26,29,30,32)$. Overall,

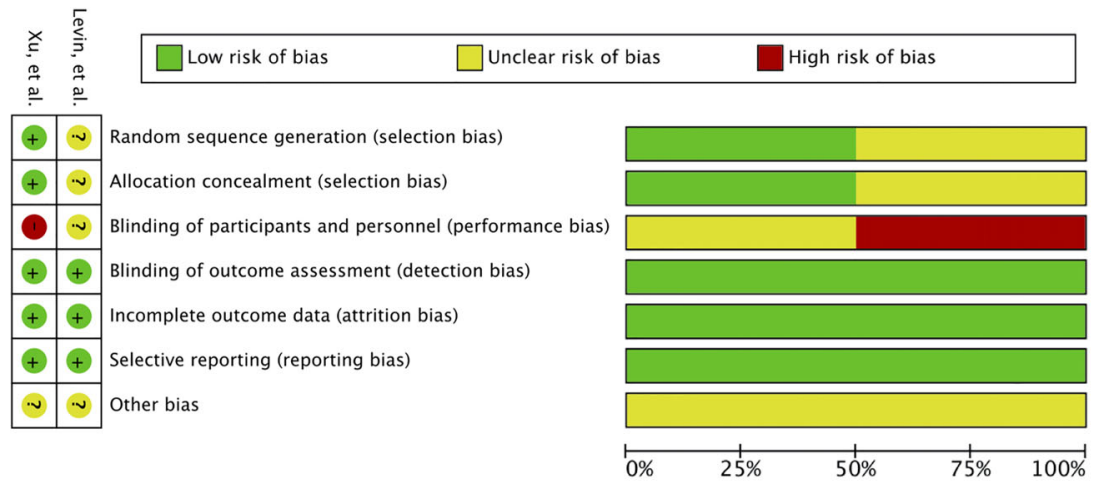

FIGURE 2 | Risk of bias assessment of two randomized controlled trials. 
TABLE 1 | General characteristics of studies and participants.

\begin{tabular}{|c|c|c|c|c|c|c|c|c|c|c|c|c|c|}
\hline Studies & Design \& Period & Location & $\begin{array}{l}\text { No. of } \\
\text { Patients }\end{array}$ & $\begin{array}{c}\text { Age } \\
\text { (mean) }\end{array}$ & Male & Female & Basic histology & Radiation & $\begin{array}{l}\text { RT to RN Diagnosis/ } \\
\text { BV Tx }\end{array}$ & RN Diagnosis & BV Dosage & $\begin{array}{l}\text { No. of } \\
\text { cycles }\end{array}$ & Follow Up \\
\hline $\begin{array}{l}\text { Gonzalez } \\
\text { et al. (22) }\end{array}$ & $\begin{array}{l}\text { Retrospective } \\
\text { Sep } 2005 \text { - May } 2006\end{array}$ & $\begin{array}{l}\text { The University of } \\
\text { Texas M. D. Anderson } \\
\text { Cancer Center, } \\
\text { Houston, USA }\end{array}$ & 8 & 54 & 4 & 4 & $\begin{array}{l}\operatorname{AOA}(1), \operatorname{AOD}(1), A A(1), \operatorname{HEPC}(1), \\
\operatorname{GBM}(4)\end{array}$ & RT/SRS & $\begin{array}{l}38.8 \text { months (RT) } \\
9 \text { months (SRS) }\end{array}$ & MRI & $\begin{array}{l}5 \mathrm{mg} / \mathrm{kg} \mathrm{q} 2 \text { week } \\
\text { OR } 7.5 \mathrm{mg} / \mathrm{kg} \mathrm{q} 3 \\
\text { week }\end{array}$ & $2-4$ & 8.1 weeks \\
\hline $\begin{array}{l}\text { Torcuator } \\
\text { et al. (23) }\end{array}$ & $\begin{array}{l}\text { Retrospective } \\
2006-2008\end{array}$ & $\begin{array}{l}\text { Henry Ford Hospital, } \\
\text { Detroit, USA }\end{array}$ & 6 & 48 & 3 & 3 & $\mathrm{~A}(1), \mathrm{AA}(1), \mathrm{AE}(1), \mathrm{GBM}(3)$ & $\begin{array}{l}\text { EBRT/FSRT/ } \\
\text { SRS }\end{array}$ & $\begin{array}{l}19.1 \text { months (EBRT) } \\
6.5 \text { months (SRS/ } \\
\text { FSRT) }\end{array}$ & MRI, biopsy & $10 \mathrm{mg} / \mathrm{kg}$ q2 week & 6.8 & 5.9 months \\
\hline $\begin{array}{l}\text { Levin et al. } \\
\text { (24) }\end{array}$ & $\mathrm{RCT}$ & $\begin{array}{l}\text { University of Texas M. } \\
\text { D, Houston, Texas, } \\
\text { USA }\end{array}$ & 7 & 47 & 5 & 2 & AA (2), OD (2), HEPC (1), SCC (1) & RT & $\geq 6$ months & MRI, biopsy & $\begin{array}{l}7.5 \mathrm{mg} / \mathrm{kg} \text { q2-3 } \\
\text { week }\end{array}$ & 4 & 10 months \\
\hline $\begin{array}{l}\text { Wang } \\
\text { et al. (25) }\end{array}$ & $\begin{array}{l}\text { Retrospective } \\
\text { Mar } 2010 \text { - Jan } 2012\end{array}$ & $\begin{array}{l}\text { Huashan Hospital, } \\
\text { Fudan University, } \\
\text { Shanghai, China }\end{array}$ & 17 & 48 & 13 & 4 & $\begin{array}{l}\text { AA (1), AOD (1), GBM (7), M (1), BM } \\
\text { (5) - (lung (2), colon (3)), AVM (1), FDB } \\
\text { (1) }\end{array}$ & $\begin{array}{l}\text { EBRT/SRS/ } \\
\text { FRST }\end{array}$ & $\begin{array}{l}34.3 \text { (EBRT) } \\
10.6 \text { (SRS/FSRT) }\end{array}$ & $\begin{array}{l}\text { MRI, MRS, } \\
\text { PET }\end{array}$ & $\begin{array}{l}7.5 \mathrm{mg} / \mathrm{kg} \mathrm{q} 2 \\
\text { week }\end{array}$ & $\begin{array}{c}4 \\
\text { (median) }\end{array}$ & 6 months \\
\hline $\begin{array}{l}\text { Boothe } \\
\text { et al. (26) }\end{array}$ & $\begin{array}{l}\text { Retrospective } \\
\text { 3-year }\end{array}$ & $\begin{array}{l}\text { Memorial Sloan- } \\
\text { Kettering Cancer } \\
\text { Center, New York, } \\
\text { USA }\end{array}$ & 11 & 58 & 4 & 7 & BM (Breast (5), NSCLC (6)) & SRS/WBRT & 12.4 months & $\begin{array}{l}\text { MRI, biopsy, } \\
\text { PET }\end{array}$ & $10 \mathrm{mg} / \mathrm{kg} \mathrm{q} 2 \mathrm{w}$ & 6 & 101 days \\
\hline $\begin{array}{l}\text { Furuse } \\
\text { et al. (27) }\end{array}$ & $\begin{array}{l}\text { Retrospective } \\
\text { Jan } 2009 \text { - Oct } 2010\end{array}$ & $\begin{array}{l}\text { Osaka Medical } \\
\text { College, Takatsuki, } \\
\text { Osaka, Japan }\end{array}$ & 11 & 57 & 6 & 5 & $\begin{array}{l}\text { BM (3), GBM (3), GBMO (1), AA (1), } \\
\text { AM (3) }\end{array}$ & $\begin{array}{l}\text { SRS/XRT/ } \\
\text { BNCT// } \\
\text { Proton/SRT }\end{array}$ & 11 months & MRI, MET-PET & $5 \mathrm{mg} / \mathrm{kg}$ q2w & 3 & 14.4 \\
\hline $\begin{array}{l}\text { Yonezawa } \\
\text { et al. (28) }\end{array}$ & $\begin{array}{l}\text { Prospective } \\
\text { Nonrandomized } \\
\text { Jun } 2010 \text { - Sep } 2011\end{array}$ & $\begin{array}{l}\text { Kizawa Memorial } \\
\text { Hospital, Minokamo, } \\
\text { Japan }\end{array}$ & 9 & 52.8 & 7 & 2 & $\begin{array}{l}\text { GBM (6) } \\
\text { BM (2) - (lung) } 2 \\
\text { AOD (1) }\end{array}$ & $\begin{array}{l}\text { HFRTMBRT/ } \\
\text { SRS/SRT }\end{array}$ & 14.1 months & MRI, MET-PET & $5 \mathrm{mg} / \mathrm{kg}$ q2w & 6 & \\
\hline $\begin{array}{l}\text { Sadraei } \\
\text { et al. (29) }\end{array}$ & $\begin{array}{l}\text { Retrospective Jul } 2007 \\
\text { - Jun } 2012\end{array}$ & $\begin{array}{l}\text { Cleveland Clinic, } \\
\text { Cleveland, Ohio, USA }\end{array}$ & 24 & 57 & 9 & 15 & $\begin{array}{l}\text { BM (17) - (lung (9), breast (4), rectal } \\
\text { (1), melanoma (1), NSTC (1), F (1)), } \\
\text { GBM (2), AOD (1), AE (1), TA (1), AVM } \\
\text { (2) }\end{array}$ & $\begin{array}{l}\text { WBRT/SRS/ } \\
\text { Proton }\end{array}$ & $\begin{array}{l}16.2 \text { months (RT) } \\
9.8 \text { months (SRS) }\end{array}$ & $\begin{array}{l}\text { MRI, PET, } \\
\text { biopsy }\end{array}$ & $\begin{array}{l}10 \mathrm{mg} \mathrm{q} 2 \mathrm{w} \text { OR } 15 \\
\mathrm{mg} / \mathrm{kg} \text { q3w (11) } \\
5 \mathrm{mg} / \mathrm{kg} \mathrm{q} 2 \mathrm{w} \text { OR } \\
7.5 \mathrm{mg} / \mathrm{kg} \mathrm{q} \mathrm{w} \\
\text { (13) }\end{array}$ & 7 & 8 months \\
\hline $\begin{array}{l}\text { Zhuang } \\
\text { et al. (30) }\end{array}$ & $\begin{array}{l}\text { Retrospective } \\
\text { Jun } 2011 \text { - Dec } 2014\end{array}$ & $\begin{array}{l}\text { Tianjin Cancer } \\
\text { Hospital, Tianjin, China }\end{array}$ & 14 & 56 & 6 & 8 & $\begin{array}{l}\text { BM (Lung (11), Breast (1), Lymphoma } \\
\text { (1), Gastric cancer (1)) }\end{array}$ & RT & & $\begin{array}{l}\text { MRI, PET, } \\
\text { pathology }\end{array}$ & $5 \mathrm{mg} / \mathrm{kg} \mathrm{q3}-4 \mathrm{w}$ & 3 & 12 months \\
\hline $\begin{array}{l}\text { Li et al. } \\
\text { (31) }\end{array}$ & Retrospective & Guangzhou, China & 50 & 50.7 & 35 & 15 & NPC & RT/MRT & $\geq 6$ months & MRI & $5 \mathrm{mg} / \mathrm{kg} \mathrm{q} 2 \mathrm{w}$ & 4 & 6 months \\
\hline $\begin{array}{l}\text { Xu et al. } \\
\text { (32) }\end{array}$ & $\begin{array}{l}\text { RCT } \\
\text { Jul } 2012 \text { - May } 2015\end{array}$ & Guangzhou, China & 58 & 49.3 & 38 & 20 & NPC & RT/IMRT & $\geq 6$ months & MRI & $5 \mathrm{mg} / \mathrm{kg}$ q2w & 4 & 6 months \\
\hline $\begin{array}{l}\text { Zhuang } \\
\text { et al. (30) }\end{array}$ & $\begin{array}{l}\text { Prospective II CT } \\
\text { Dec } 2016 \text { - Feb } 2019\end{array}$ & $\begin{array}{l}\text { Tianjin Cancer } \\
\text { Hospital, Tianjin, China }\end{array}$ & 21 & $\begin{array}{l}55 \\
\text { (median, } \\
\text { range } \\
43-70)\end{array}$ & 11 & 10 & $\begin{array}{l}\text { BM (lung (17), breast (2), kidney } \\
\text { cancer (2)) }\end{array}$ & SRT & 17.6 & MRI & $1 \mathrm{mg} / \mathrm{kg} \mathrm{q} 3 \mathrm{w}$ & 3 & 22.7 \\
\hline This study & & & 236 & & 141 & 95 & & & & & & $2-7$ & \\
\hline
\end{tabular}

A, astrocytoma; $A O A$, anaplastic oligoastrocytoma; $O D$, oligodendroglioma; $A O D$, anaplastic oligodendroglioma; $A$, anaplastic astrocytoma; GBM, glioblastoma; GBMO, glioblastoma multiforme with oligodendroglial component; $A$, astrocytoma; HEPC, hemangiopericytoma; AE, anaplastic ependymoma; $M$, meningioma; AM, anaplastic meningioma; SCC, squamous cell carcinoma; BM, brain metastases; AVM, arteriovenous malformation; FDB, fibrous dysplasia of bone; NSTC, non-seminomatous testicular cancer; FT, fallopian tube; TA, tectal astrocytoma; RT, radiotherapy; SRS, stereotactic radiosurgery; WBRT, whole-brain radiotherapy; XRT, X-ray radiotherapy; EBRT, electron beam radiotherapy; FSRT, fractionated stereotactic radiosurgery; HFRT, hypo-fractionated radiotherapy; SRT, stereotactic radiotherapy; BNCT, boron neuron capture therapy; NPC, nasopharyngeal carcinoma. 


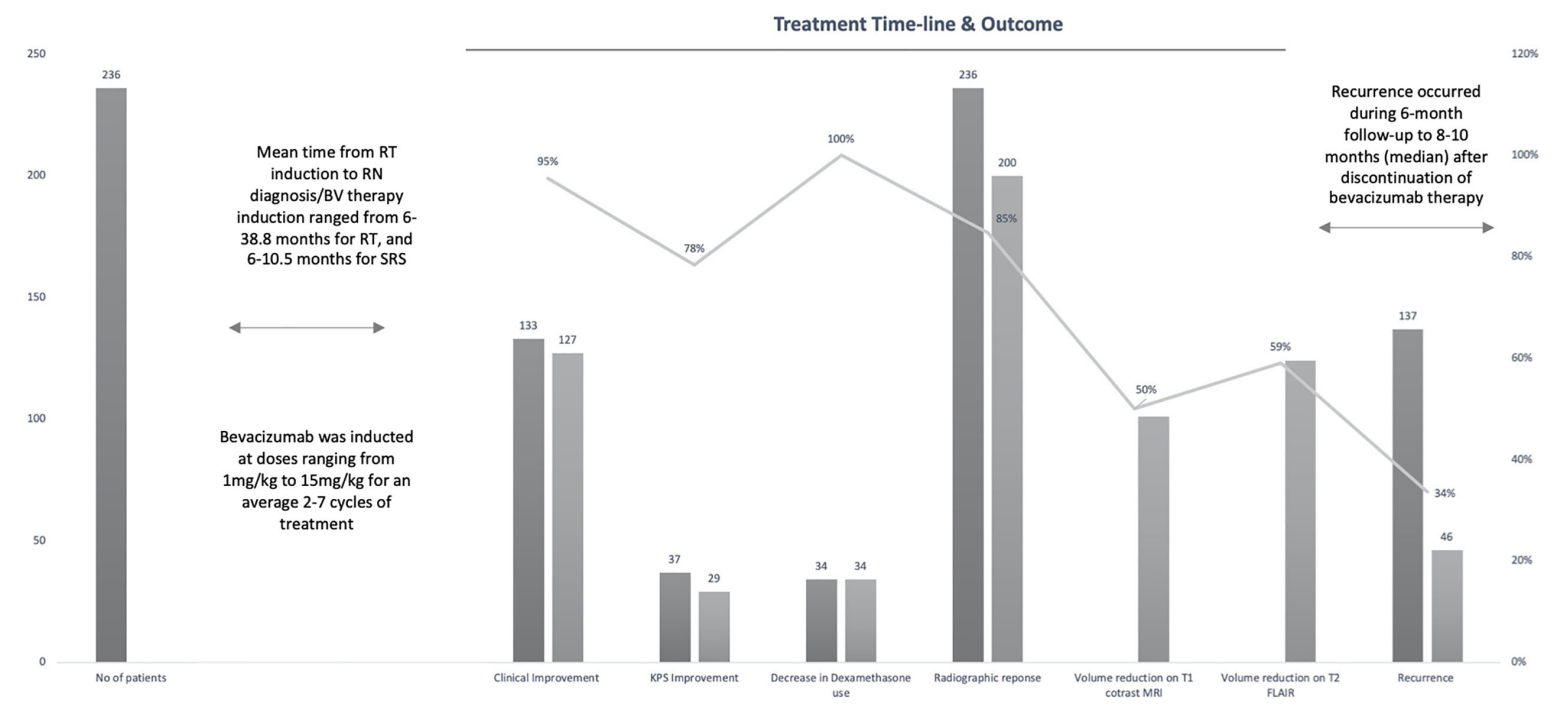

FIGURE 4 | Graph showing timeline of entire study population from radiation therapy (RT) induction to radiation necrosis (RN) diagnosis/bevacizumab (BV) treatment to recurrence with main outcomes of interest.

127 patients (95\%) demonstrated an improvement in clinical outcomes. Thirteen patients (9\%) achieved a stable outlook, 106 (79.7\%) showed improvement in symptoms, and eight (6\%) experienced symptom resolution (23-26, 29, 30, 32). Further details are presented in Table 3 . Two studies $(n=35)$ also analyzed improvement in symptomatic grades after bevacizumab therapy $(30,33)$. In a retrospective study by Zhuang et al. $(n=14)$, 10 patients $(83.3 \%)$ had significantly reduced symptom grades after bevacizumab therapy $(\mathrm{t}=5.657 ; \mathrm{p}=0.000)(30)$. In a prospective phase II trial by the same authors, 18 patients (90\%) showed a significant decrease in the severity of their symptoms after bevacizumab induction $(t=5.657$; $\mathrm{p}<0.001)(33)$.

Bevacizumab was significantly better than corticosteroids, as revealed in the RCT conducted by Xu et al. (32), who reported significant clinical improvement in 36 patients $(62.1 \%)$ treated with bevacizumab and in 23 patients $(42.6 \%)$ treated with corticosteroids $(p=0.039$ ). Levin et al. also observed clinical improvement in $100 \%$ of patients treated with bevacizumab, but in none who were treated with a placebo (0\%) (Table 2) (24).

\section{Improvement in KPS Score}

Individual KPS scores were assessed in three studies involving 37 patients $(25,27,28)$, all but eight of whom showed an increase in KPS score after treatment with bevacizumab (Table 3). The average increase in KPS score across the three studies ranged from 10 to $24.7(25,27,28)$.

\section{Decrease in Dexamethasone Dosage}

Five studies evaluated the tapering of dexamethasone (Table 3) (22-26). Three studies involving 34 patients reported individual scores for changes in dexamethasone dosage $(22,25,26)$. All patients registered a decrease in steroid use. The average decrease for the studies ranged from 8.6 to $9.4 \mathrm{mg}$ (Table 3 ).

\section{Radiographic Response}

All studies reported radiographic responses after bevacizumab use (22-33). Overall, 200 patients (84.7\%) showed radiographic responses after the induction of bevacizumab, while 36 patients (15.3\%) experienced radiographic progression (Table 4). Of the 36 patients with progressive disease, 32 had NPC $(31,32)$. Six studies including 52 patients revealed a $100 \%$ radiographic response (22-24, 26-28). Two studies involving NPC patients $(\mathrm{n}=108)$ reported the lowest response rates (Li et al.: 76\% [38/ 50]; Xu et al.: $65.5 \%$ [38/58]) $(31,32)$.

The radiographic response was significantly better in patients receiving bevacizumab than in those given corticosteroids (24, $32)$. Levin et al. $(n=14)$ reported significantly better responses in patients treated with bevacizumab than in the placebo group $(100 \%$ vs. $0 \% ; \mathrm{p}=0.0013)(24) . \mathrm{Xu}$ et al. $(\mathrm{n}=112)$ identified a similar significant response in patients treated with bevacizumab (65.5\% vs. $31.5 \%$; p < 0.001) (32).

\section{MRI Changes}

All 12 studies reported volume reduction on T1 Gd enhancement and/or T2 FLAIR MRI images (22-33). A median reduction of 50\%, with a range of $26 \%-80 \%$, was observed on T1 Gd enhancement MRI in 10 studies $(22-26,28-30,32,33)$ (Table 4). Similarly, T2 FLAIR MRI showed a median volume reduction of 59\%, with a range of $48 \%-74 \%$, in 12 studies (22-33). The volume reduction in contrast studies and flair images in all studies are illustrated in Table 4.

Several studies have also reported significant MRI volume reduction after bevacizumab therapy initiation (28, 30-32). In patients with NPC, significant volume reduction was seen in both MRI images after bevacizumab treatment (T1: 25.5\%, p < 0.001; T2: 51.8\%, p < 0.001) (32). Yonezawa et al. $(n=9)$ also identified a significant reduction in both MRI images after 
TABLE 2 | Comparison of bevacizumab and corticosteroid-based treatment of radiation induced necrosis.

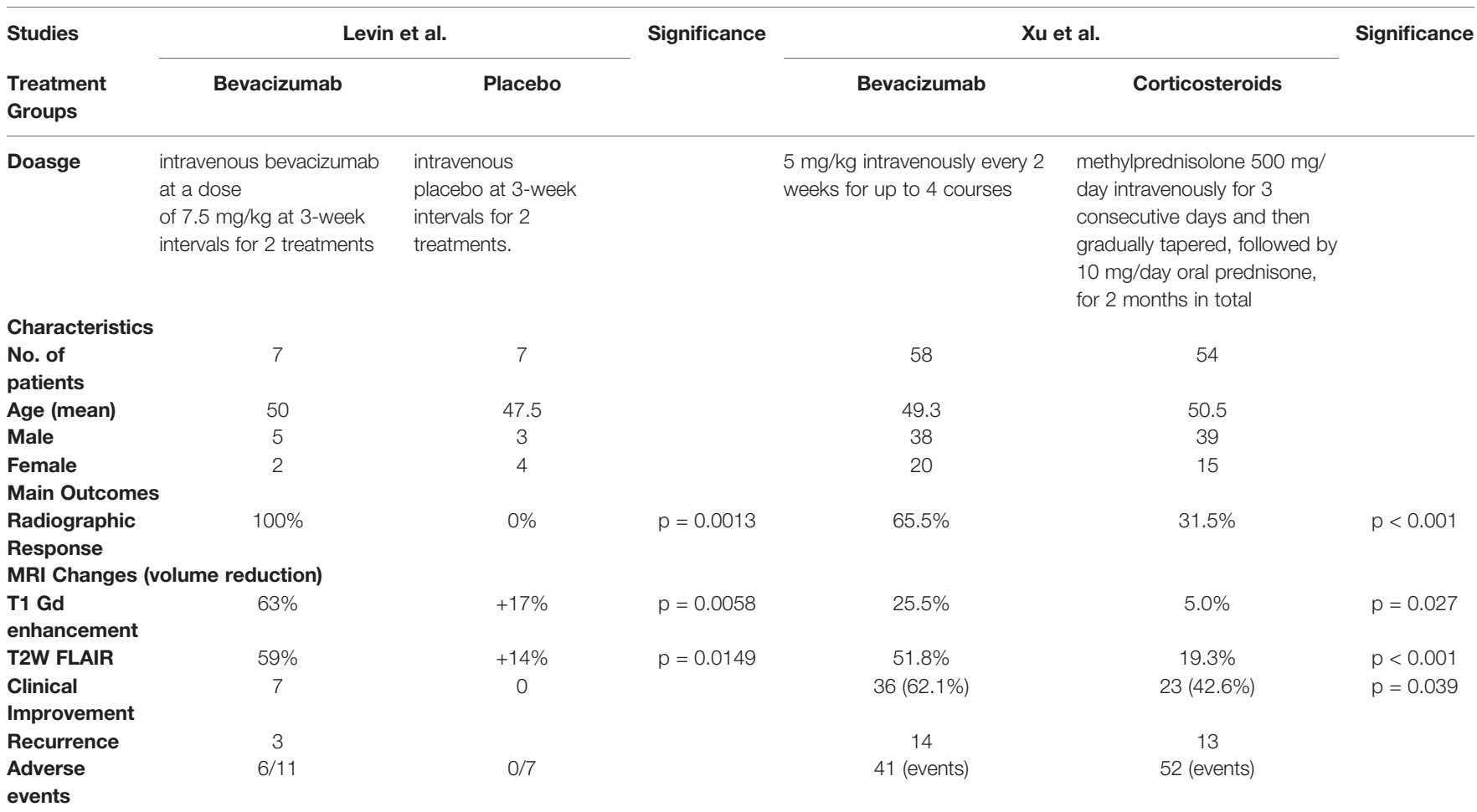

bevacizumab induction (T1: $80 \%, \mathrm{p}=0.01$; $\mathrm{T} 2: 65 \%, \mathrm{p}<0.001$ ) (28). The mean reduction in edema index was significant in $64.3 \%$ of patients in the study by Zhuang et al. $(p=0.002)(30)$. Similarly, a study by Li et al. $(\mathrm{n}=38)$ reported a significant mean reduction in volume under T2-weighted FLAIR MRI (72.6\%; $\mathrm{p}<$ 0.001) (31).

$\mathrm{Xu}$ et al. reported that 38 of 58 patients $(65.5 \%)$ in the bevacizumab group had a mean $25.5 \%$ reduction in edema volume on T1 post-Gd MRI and a mean $51.8 \%$ reduction on T2-weighted FLAIR images (32). In contrast, the corticosteroid group achieved reductions of only $5.0 \%$ and $19.3 \%$ on T1 Gd enhancement and T2-weighted FLAIR MRI, respectively (32). This difference was significant (Table 2). Levin et al. reported a mean T2 FLAIR edema volume reduction of $59 \%$ across all patients $(5 / 5 ; 100 \%)$ randomized to receive bevacizumab (24), while all patients in the control group (7/7 patients; 100\%) showed a mean increase of $14 \%$ in T2 FLAIR edema volume ( $\mathrm{p}=0.0149$; Table 2). Bevacizumab treatment reduced the T1enhancement volume by $63 \%$, while the control group saw a $17 \%$ increase $(\mathrm{p}=0.0058)(24)$.

\section{Necrosis Recurrence}

Overall, six studies involving 135 patients reported the recurrence rates following bevacizumab therapy for RBN (24, $25,29-32)$. In total, 46 responding patients (34\%) had recurrence after showing improvement with bevacizumab therapy (Figure 4). The highest recurrence rate was observed in patients with brain metastasis (10 of 14 patients) (30). Ten patients were reported to have recurrence during a median follow-up time of 10 months (1.2-38 months) after discontinuation of bevacizumab therapy. Three of the five patients responded to retreatment with bevacizumab (30). Patients with NPC who responded to bevacizumab treatment also had a high recurrence rate (Li et al.: 15/38 [39.5\%]; Xu et al.: 14/38 [36.8\%]) $(31,32)$. During the 6-month follow-up, 14 of 58 patients had recurrence (32). Four patients $(17.3 \%)$ experienced recurrence in the study by Sadraei et al. (29). The median time of $\mathrm{RBN}$ recurrence was 8 months (range: 6-16 months) in these four patients who had neurological deterioration after initial response to bevacizumab (29). All four patients responded to bevacizumab rechallenge, and one experienced RBN recurrence for the third time after 4 months of treatment (29). The patient responded and showed clinical improvement with a third bevacizumab therapy (29). One patient in the study by Wang et al. $(\mathrm{n}=17)$, and two randomized to receive bevacizumab in the study by Levin et al., also had RBN recurrence. No other studies mentioned recurrence in their assessments $(22,23,26-28,33)$.

The recurrence rate of bevacizumab did not differ significantly from that of corticosteroids or placebo. $\mathrm{Xu}$ et al. reported that 14 of 58 patients in the bevacizumab group and 13 of 54 patients in the control group experienced necrosis recurrence during the 6-month follow-up (32). Levin et al. reported that two of seven patients originally randomized to receive bevacizumab treatment had $\mathrm{RBN}$ recurrence (24). Comparison with the placebo group could not be carried out in that study as all patients in the placebo group had progression upon treatment initiation, and six of them were crossed over to 


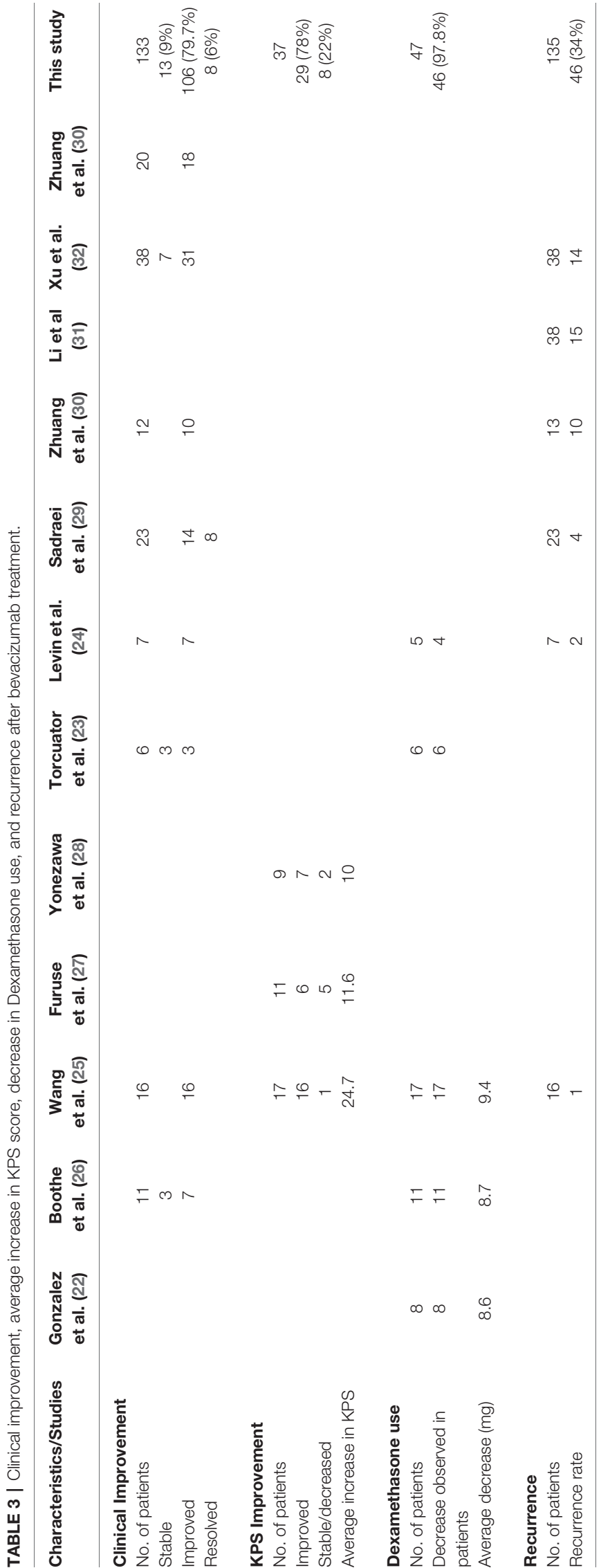

the bevacizumab group. Overall, 25\% (3/12) of recurrences were observed in patients from the placebo group, including the crossed over patients (24).

\section{Adverse Events}

Adverse events related to bevacizumab were reported in seven of the included studies $(23-25,28-30,32)$. Most of the side effects were grade 1 or 2 . The most common symptoms were hypertension, fatigue, proteinuria, and ischemic changes (23$25,29,30,32)$. Two grade 3 events were reported: pulmonary embolism and ischemic stroke $(29,32)$. Other less frequent side effects are presented in Table 5.

Levin et al. reported no adverse events in $7 / 7$ patients who received placebo, but that $6 / 11$ patients receiving bevacizumab had adverse events, including the six patients who had crossed over to the bevacizumab group (24). Hence, no comparison can be made based on these data. Xu et al. indicated that the two groups had similar rates of adverse events (32). Patients receiving bevacizumab experienced 41 adverse events, whereas the corticosteroid group reported 52 events.

\section{Improvement in Cognitive Function}

Improvement in cognitive function was only assessed in RCTs comparing bevacizumab with placebo/corticosteroids $(24,32)$. Between-group differences in the change scores of medium to large effect size (Cohen's $d \geq 0.5$ ) revealed that bevacizumabtreated patients had greater improvement than the placebo group in a learning trial (Hopkins Verbal Learning TestRevised [HVLT-R] total recall) (Cohen's $\mathrm{d}=0.59 ; \mathrm{p}=0.26$ ) and a delayed recognition memory trial (HVLT-R delayed recognition; Cohen's $d=0.92 ; \mathrm{p}=0.08)$, as well as improved symptom severity ratings (MD Anderson Symptom Inventory [MDASI]-Severity; Cohen's $d=0.68 ; \mathrm{p}=0.19)$. On the other hand, Levin et al. indicated that all bevacizumab-treated patients (11 patients; 100\%) exhibited worse performance on the memory measure in the delayed free recall trial (HVLT-R delayed recall), which had a low effect size (Cohen's $d=-1.05$ ), whereas all placebo-treated patients (seven patients; 100\%) showed improvement (24). Independent sample t-tests on change scores demonstrated that this difference was of borderline statistical significance $(p=0.052)$. All bevacizumab-treated patients (11 patients; $100 \%$ ) also reported experiencing greater interference in their everyday activities due to their symptoms (MDASI-Interference) in comparison to the placebo-treated patients ( $7 / 7$ patients, $100 \%$; Cohen's $d=-0.81 ; \mathrm{p}=0.13$ ).

The Montreal Cognitive Assessment (MoCA) scale was used to assess cognitive function by $\mathrm{Xu}$ et al. (32). At baseline, 21 of 58 patients $(36.2 \%)$ in the bevacizumab group and 16 of 54 patients (29.6\%) in the corticosteroid group had MoCA scores $<26$, with no significant difference between the groups. After 2 months of treatment, 28 of 58 patients (48.3\%) in the bevacizumab group had improved MoCA scores, with a mean score change of $0.71 \pm$ 2.02. On the other hand, 10 of 54 patients $(18.5 \%)$ in the corticosteroid group showed improved MoCA scores, with a mean change of $0.00 \pm 0.91(\mathrm{p}=0.028)$. 
TABLE 4 | Radiographic responses and MRI changes after treatment with bevacizumab.

\begin{tabular}{|c|c|c|c|c|}
\hline Studies & No of patients & Radiographic responses & T1 Gd enhancement volume reduction (mean) & T2 FLAIR volumereduction (mean) \\
\hline Gonzalez et al. (22) & 8 & $100 \%$ & $48 \%$ & $60 \%$ \\
\hline Torcuator et al. (23) & 6 & $100 \%$ & $79 \%$ & $49 \%$ \\
\hline Levin et al. (24) & 7 & $100 \%$ & $63 \%$ & $59 \%$ \\
\hline Wang et al. (25) & 17 & $16(94.1 \%)$ & $54.9 \%$ & $48.4 \%$ \\
\hline Boothe et al. (26) & 11 & $100 \%$ & & $65.5 \%$ \\
\hline Furuse et al. (27) & 11 & $100 \%$ & $52.2 \%$ & $56.7 \%$ \\
\hline Yonezawa et al. (28) & 9 & $100 \%$ & $80 \%(p=0.01)$ & $65 \%(p<0.001)$ \\
\hline Sadraei et al. (29) & 24 & $23(95.8 \%)$ & $48.1 \%$ & $53.7 \%$ \\
\hline Zhuang et al. (30) & 14 & $13(92.9 \%)$ & $36 \%$ & $59 \%$ \\
\hline Li et al. (31) & 50 & 38 (76.0\%) & & $72.6 \%(p<0.001)$ \\
\hline Xu et al. (32) & 58 & $38(65.5 \%)$ & $25.5 \%(p<0.001)$ & $51.8 \%(p<0.001)$ \\
\hline Zhuang et al. (30) & 21 & $20(95.3 \%)$ & $35 \%$ & $74 \%$ \\
\hline This study & 236 & 200 & Median 50\%, Range 55\% (26-80\%) & Median 59\%, Range 26\% (48-74\%) \\
\hline
\end{tabular}

TABLE 5 | Adverse events reported with bevacizumab treatment.

\begin{tabular}{|c|c|c|}
\hline Studies & Patients & Symptoms \\
\hline $\begin{array}{l}\text { Torcuator et al. } \\
\text { (23) }\end{array}$ & $1(17 \%)$ & Fatigue (1) \\
\hline Levin et al. (24) & $6(55 \%)$ & $\begin{array}{l}\text { Aspiration pneumonia (1), pulmonary embolus } \\
\text { secondary to DVT (1), superior sagittal sinus } \\
\text { thrombosis (1), ischemic changes due to small } \\
\text { vessel thrombosis (3) }\end{array}$ \\
\hline Wang et al. (25) & $3(18 \%)$ & $\begin{array}{l}\text { Grade } 2 \text { AEs: } \\
\text { hypertension (1), fatigue (1), proteinuria (1) }\end{array}$ \\
\hline $\begin{array}{l}\text { Yonezawa et al. } \\
\text { (28) }\end{array}$ & 3 (33\%) & $\begin{array}{l}\text { Grade } 1 \text { or } 2 \text { : anemia, leukopenia, neutropenia, } \\
\text { and lymphocytopenia }\end{array}$ \\
\hline Sadraei et al. (29) & 7 (29\%) & $\begin{array}{l}\text { Grade } 2 \text { or less: hypertension, fatigue, urinary } \\
\text { tract infection, and proteinuria (6). } \\
\text { Grade 3: pulmonary embolism (1) }\end{array}$ \\
\hline Zhuang et al. (30) & $2(14 \%)$ & Mild allergy, hypertension \\
\hline Xu et al. (32) & & $\begin{array}{l}\text { Grade } 1 \text { or } 2 \text { : hypertension (12), fatigue (7), } \\
\text { infection (4), hemorrhage (4), insomnia (3), } \\
\text { headache (3), rash (3), fever (2), blurred vision } \\
\text { (1), hyperglycemia (1). } \\
\text { Grade } 3 \text { : Ischemic stroke (1). }\end{array}$ \\
\hline
\end{tabular}

\section{DISCUSSION}

RBN is a late complication that can follow radiotherapy in all or parts of the brain $(34,35)$. Incidence rates of $5 \%-59 \%$ have been reported $(7,36-41)$. The incidence of RBN is affected by multiple factors, including the radiotherapy modality, the dose of radiation, the dose of fraction, the adjuvant treatment received (chemotherapy, immunotherapy, and targeted therapy), and the diagnostic methods used $(7,36-44)$. RBN is a dose-limiting factor in SRS, and an incidence rate of approximately $10 \%$ to $25 \%$ has been reported after SRS, depending on the length of follow-up $(7,36,37,42,45,46)$. Diagnostic methods have also defined contrast incidence rates $(41,43,44)$. An incidence rate of $7 \%$ was observed in studies where pathological confirmation or temporal resolution was mandatory (43). Minniti et al. reported an RBN incidence rate of $24 \%$ ( $14 \%$ symptomatic, $10 \%$ asymptomatic). They relied on imaging features for RBN diagnosis, such as contrast enhancement, absence of progression for $>4$ months, and reduced perfusion on dynamic MRI sequences (44).
Therefore, determining the incidence rate of RBN is complex and requires the assessment of various contributing factors.

The treatment options for RBN include corticosteroids, bevacizumab, hyperbaric oxygen therapy, surgical resection, and laser-induced thermal therapy (35, 38, 39, 47-50). Corticosteroids are the first-line treatment for RBN as they effectively inhibit the pro-inflammatory response that propagates necrosis and reduces the leakiness of the bloodbrain-barrier $(34,47)$. Symptomatic relief is achieved via edema reduction; however, long-term use results in steroid myopathy, osteopenia, gastric ulcers, glucose intolerance, and iatrogenic Cushing's syndrome (48). The rationale for using hyperbaric oxygen therapy to treat cerebral radiation necrosis is that increasing the oxygen concentration stimulates angiogenesis and restores the blood supply to the necrotic lesion, thereby promoting healing $(38,49-53)$. However, evidence for the efficacy of this approach mainly relies on case reports, with no class I evidence (49-52). Simultaneously, this treatment is expensive, longer lasting, and requires special facilities, so it is less desirable and feasible in clinical practice. Surgery is also an important method for managing progressive resectable radiation necrosis lesions as it can relieve the effects of the mass itself $(35,38,39,53,54)$. It also allows tissue diagnosis and can be used to rule out tumor progression by biopsy $(35,38)$. However, even after surgical resection, brain edema may persist for a few weeks and require close monitoring $(35,38,53,54)$. Recently, laser interstitial thermal therapy and anti-VEGF targeted inhibitors have been used in addition to surgery to treat RBN $(38,55)$. Various studies have shown clinical improvement and enhanced progression-free survival and overall survival rates with laser interstitial thermal therapy (56-58). Nevertheless, treatment guidelines in patients with RBN are inconsistent, so further class I evidence is required, including RCTs, to establish the role of each treatment modality.

Recently, the efficacy of bevacizumab in RBN treatment has been investigated (12-33). Several case reports and case series have reported a positive response to bevacizumab treatment (1219). We systematically reviewed the literature for studies that clinically evaluated patients with RBN who were treated with bevacizumab. We obtained 12 studies, with a total population of 236 patients (22-33). The radiographic response to bevacizumab 
was nearly $97 \%$, excluding patients with NPC (22-30), who had a $70 \%$ response to bevacizumab treatment $(31,32)$. The responding patients demonstrated edema volume reduction under T1 Gd enhancement (median: 50\%, range: 26\%-80\%) and T2-weighted FLAIR MRI images (median: 59\%, range: $48 \%-$ $74 \%)(22-33)$. Some of these studies found that the volume reduction was significant on both MRI images after bevacizumab treatment (28, 30-32). Furthermore, both RCTs demonstrated that the reduction induced by bevacizumab treatment was significantly superior to that induced by corticosteroids $(24,32)$.

The radiographic response was correlated with clinical improvement, as $91 \%$ of the patients with radiographic response had either stabilized clinical outlook or improved and resolved neurological symptoms and signs (23-26, 29-33). The improvement could also be reflected in the increase seen in the individual KPS scores of 29 patients (79\%) after bevacizumab treatment $(25,27,28)$. A significant decrease in the use of dexamethasone was also observed in each individual patient in the five studies that reported this variable (22-26).

Although the literature is limited in this regard, several case reports and case series have yielded similar efficacy data (12-19, 59-61). One systematic review assessed 16 studies, including seven single-case reports and a total of 71 unique RBN cases reported between 2007 and 2012. That study revealed similar efficacy data for bevacizumab in the management of RBN (15). A radiographic response of $97 \%$ in $79 \%$ of patients showed improvement in performance status. The KPS improvement was 10 points (range: $0-40$ ), and a 6-mg (range: 0-24 mg) decrease in dexamethasone use was noted. Median decreases of $63 \%$ and $59 \%$ in $\mathrm{T} 1$ contrast enhancement and T2/FLAIR signal abnormality, respectively, was revealed after treatment (15). A recently published case report of four ALK-positive lung cancer patients with RBN revealed that all of the patients had seen a decrease in RBN and that three had experienced symptom improvement after bevacizumab (15 mg/kg every 3-4 weeks) was added to their ALK-TKI therapy (59). Administration of lower bevacizumab doses ( 2 x $7.5 \mathrm{mg} / \mathrm{kg}$ every 3 weeks) also resulted in complete resolution of physical signs in two patients (one with metastatic lung cancer and another with NPC), as well as a transient improvement in signs and symptoms in two other patients with primary brain tumor (19). A case report of two melanoma patients with brain metastasis and symptomatic RBN showed clinical improvement and discontinuation of dexamethasone after initial doses of $5 \mathrm{mg} / \mathrm{kg}$ every 2 weeks (18). Bevacizumab has also shown responses in patients with steroid-refractory $\mathrm{RBN}(16,17,60,61)$. A case series of four patients with high-grade glioma, who had developed cerebral edema due to tumor progression or radiation necrosis and were either not responding to corticosteroids or were not candidates for surgical debulking, showed rapid responses to bevacizumab treatment (17). Radiographic changes were observed on both T1 and T2 MRI images in all four patients, and three of them also showed a reduction in dexamethasone use (17). Similarly, in a retrospective study, bevacizumab was administered to 17 patients with radiation-induced brain edema refractory to steroids (61). The bevacizumab was administered at an increasing dose every 2 weeks $(5-7.5-10 \mathrm{mg} / \mathrm{kg})$. Approximately $82 \%$ of the patients showed clinical improvement, and the majority showed improvement after the third dose (61). In our systematic review, some patients did not show any clinical improvement or experienced symptomatic worsening and progression. The medical literature reveals similar examples. In a study by Gronier et al., no clinical improvement was observed in any of three patients with malignant brain tumors after bevacizumab therapy (10 mg/kg per month) (62). One patient experienced lymphopenia after one perfusion of bevacizumab; the other developed a transient ischemic attack and a corneal ulcer (62).

With regards to neurological function, formal neurocognitive testing revealed a mixed pattern of findings from both objective tests of neurocognitive function and self-reported measures of symptoms, as reported by Levin et al. (24). There was a trend toward improvement in aspects of learning and memory after 6 weeks of therapy, suggesting improved memory encoding and retention despite increased deficits in memory retrieval. This pattern suggests dysfunction in the frontal subcortical systems. However, these findings might also be explained by the small sample size of both groups. On the other hand, $\mathrm{Xu}$ et al. reported a greater improvement in bevacizumab-treated patients, as assessed using the MoCA scale (32). These outcomes indicate that bevacizumab treatment is safe and that it enhances neurocognitive functions. Similarly, two case series reports showed that bevacizumab can alleviate neurocognitive deficits (19). In the first, administration of bevacizumab (500 mg twice) sufficiently improved memory loss and reversed lower extremity weakness. In the second, the Mini-Mental State Examination score was elevated after administration of $400 \mathrm{mg}$ bevacizumab twice. In both cases, improvements were evident on MRI imaging.

In many studies, bevacizumab has elicited a therapeutic response and clinical improvement at any prescribed dose ranging from $1 \mathrm{mg} / \mathrm{kg}$ to $15 \mathrm{mg} / \mathrm{kg}$ (12-19, 22-33, 59-61). The duration between each cycle has also varied, ranging from every 2 weeks to every 6 weeks. Zhuang et al. suggested that bevacizumab efficacy is associated with its anti-angiogenic effects rather than the dose (33). A previous systematic review recommended an initial dose of $7.5 \mathrm{mg} / \mathrm{kg}$ every 2 weeks for four cycles to treat patients with RBN (15). Tripathi et al. suggested that, to achieve the best response, an average of seven cycles (range: 5-27) of bevacizumab should be administered (61). Our study also indicated that bevacizumab should be administered for up to seven cycles on average (Table 1) (22-33). However, prolonged treatment should be avoided, as paradoxical phenomena have also been reported $(16,63)$. In a case report, exacerbation of RBN was noted after the initial response to bevacizumab (16). The authors speculated that there had been initial cerebral edema reduction, but that prolonged treatment caused over-pruning of at-risk blood vessels within the radiation field (16). Over-pruning likely leads to vascular insufficiency, which can exacerbate hypoxia and necrosis (63).

In the present study, $34 \%$ of the radiographically responsive patients experienced recurrence, based on the results of six studies $(24,25,29-32)$. The underlying cause of recurrence was not identified in any of the studies. Li et al. indicated that the 
duration between radiotherapy and bevacizumab intervention and the duration between radiotherapy and RBN diagnosis were predictive factors for the recurrence of $\mathrm{RBN}$ after bevacizumab treatment (31). In another study, recurrence of RBN after bevacizumab treatment was correlated with the time since initial bevacizumab withdrawal (64). As with the primary diagnosis of $\mathrm{RBN}, \mathrm{RBN}$ recurrence is difficult to differentiate from a tumor (39, 65-68). In a study of 14 patients with brain metastasis, 10 of the 13 responsive patients (76.9\%) experienced a recurrence of RBN during follow-up (30). Similarly, two studies involving patients with NPC reported a high recurrence rate $(36 \%-38 \%)(31,32)$. Although the two studies differed in research design (one retrospective, one RCT), the results were very consistent $(31,32)$. In the comparative RCT, both patients receiving bevacizumab and corticosteroids experienced similar recurrence rates (32), indicating that $\mathrm{RBN}$ recurrence may not prove failure of bevacizumab treatment. Nonetheless, no pathological confirmation was sought to confirm the RBN recurrence in these studies (30-32). In a case report, a 55-year-old man experienced re-enlargement of RBN after 8 months of bevacizumab therapy (69). This re-enlargement was attributed to the recurrence of lung cancer, as histopathological analysis of the resected specimen revealed large necrotic areas with viable tumor cells (69). Hence, an accurate recurrence rate could only be determined by pathology, which should be further examined in larger, comprehensively organized trials.

Retrospective studies reported side effects ranging in 14\%$33 \%$ of patients after bevacizumab treatment $(23,25,28-30)$. The side effects were mostly grade 1 or 2 , with only one grade 3 : pulmonary embolism $(23,25,28-30)$. A previous study also reported a similar low percentage of grade 3 or 4 toxicities $(2.3 \%)$ (64). The two RCTs showed an increased number of side effects, but they were low grade $(24,32)$. In the study by Levin et al., adverse events occurred in $55 \%$ of patients $(6 / 11)$ in the bevacizumab group; however, this number also included crossed-over placebo patients (24). Similarly, Xu et al. found that bevacizumab treatment caused no more side effects than corticosteroid-treatment (32). Therefore, bevacizumab may not increase the risk of serious side effects in patients with RBN.

Bevacizumab is used to treat $\mathrm{RBN}$ because $\mathrm{RBN}$ tissues have elevated levels of VEGF $(70,71)$. However, circulating levels of VEGF did not predict the therapeutic efficacy of bevacizumab in a study by Li et al. (31). The pre- and post-bevacizumab VEGF levels in responsive and non-responsive patients revealed no differences $(68.0 \pm 13.1 \mathrm{pg} / \mathrm{mL}$ vs. $68.1 \pm 21.3 \mathrm{pg} / \mathrm{mL} ; \mathrm{p}=0.950)$. Moreover, VEGF levels did not predict recurrence, as patients with recurrence showed no difference in serum VEGF levels from those without recurrence $(66.8 \pm 11.1 \mathrm{pg} / \mathrm{mL}$ vs. $69.2 \pm 14.4 \mathrm{pg} /$ $\mathrm{mL} ; \mathrm{p}=0.931)(31)$.

Several factors limited our analysis. Firstly, most of the studies were retrospective in nature and contained few patients $(22,23,25-$ 27, 29-31). Retrospective studies are prone to selection bias, recall bias, and misclassification bias, and they are subject to confounding (72). Furthermore, patients had different conditions for undergoing radiotherapy; radiation modalities and doses also differed greatly among the studies and patients (22-32). The follow-up after bevacizumab therapy also varied and was limited (22-32). The patients were most often diagnosed using radiological evaluation in the included studies (22-33). Publication bias may also have been present, as patients responding to bevacizumab were more likely to be included in the studies $(22,23,25-27,29-31)$. To assess comparative outcomes, only two RCTs were available. Even though it was classified as class I evidence, the study by Levin et al. comprised only 14 patients and a high crossover from the placebo group. The second RCT was downgraded one level as it was open-label; it was then further downgraded due to concerns regarding detection bias and inadequate blinding in the trial (32).

\section{CONCLUSIONS}

In conclusion, patients with $\mathrm{RBN}$ respond to bevacizumab treatment. Bevacizumab improves the neurological symptoms in patients with RBN, as well as performance as measured using the KPS scale. Patients ultimately either discontinued or tapered the use of dexamethasone. Although several studies were retrospective, their efficacy data were consistent with the RCT results. The improvement was also evident on MRI images, with a significant reduction in edema volumes. The results of the two RCTs suggested that bevacizumab treatment had superior efficacy than placebo or corticosteroids. Importantly, bevacizumab could improve neurocognition. Currently, a randomized controlled trial is ongoing, comparing bevacizumab plus corticosteroids with corticosteroids plus placebo. This trial which will certainly provide more evidence for the comparative efficacy of bevacizumab (NCT02490878). There were no serious side effects associated with bevacizumab administration. The safety profile was comparable to that of the corticosteroids. More well-designed and larger RCTs are required to fully establish the role of bevacizumab in $\mathrm{RBN}$ treatment.

\section{DATA AVAILABILITY STATEMENT}

The original contributions presented in the study are included in the article/supplementary material. Further inquiries can be directed to the corresponding authors.

\section{AUTHOR CONTRIBUTIONS}

GL, MK, and ZZ provided manuscript writing, data searched and data analysis. All authors corrected and proofed the final text. All authors contributed to the article and approved the submitted version.

\section{FUNDING}

The Natural Science Foundation of Shenzhen (No. JCYJ20170307095828424) and Shenzhen Health and Family Planning System Research Project (No. SZBC2017024) were providing support for this work. 


\section{REFERENCES}

1. Zalutsky MR. Targeted radiotherapy of brain tumours. Br J Cancer (2004) 90 (8):1469-73. doi: 10.1038/sj.bjc.6601771

2. Khan M, Lin J, Liao G, Li R, Wang B, Xie G, et al. Comparison of WBRT alone, SRS alone, and their combination in the treatment of one or more brain metastases: Review and meta-analysis. Tumour Biol J Int Soc Oncodevelopmental Biol Med (2017) 39(7):1010428317702903. doi: 10.1177/ 1010428317702903

3. Greene-Schloesser D, Robbins ME, Peiffer AM, Shaw EG, Wheeler KT, Chan MD. Radiation-induced brain injury: A review. Front Oncol (2012) 2:73. doi: $10.3389 /$ fonc. 2012.00073

4. Tofilon PJ, Fike JR. The radioresponse of the central nervous system: a dynamic process. Radiat Res (2000) 153(4):357-70. doi: 10.1667/0033-7587 (2000)153[0357:TROTCN]2.0.CO;2

5. Khan M, Lin J, Liao G, Tian Y, Liang Y, Li R, et al. SRS in Combination With Ipilimumab: A Promising New Dimension for Treating Melanoma Brain Metastases. Technol Cancer Res Treat (2018) 17:1533033818798792. doi: $10.1177 / 1533033818798792$

6. Schultheiss TE, Stephens LC. Invited review: permanent radiation myelopathy. Br J Radiol (1992) 65(777):737-53. doi: 10.1259/0007-1285-65777-737

7. Loganadane G, Dhermain F, Louvel G, Kauv P, Deutsch E, Le Péchoux C, et al. Brain Radiation Necrosis: Current Management With a Focus on Nonsmall Cell Lung Cancer Patients. Front Oncol (2018) 8:336. doi: 10.3389/ fonc. 2018.00336

8. Khan M, Zhao Z, Arooj S, Liao G. Impact of Tyrosine Kinase Inhibitors (TKIs) Combined With Radiation Therapy for the Management of Brain Metastases From Renal Cell Carcinoma. Front Oncol (2020) 10:1246. doi: $10.3389 /$ fonc. 2020.01246

9. Weingarten N, Kruser TJ, Bloch O. Symptomatic radiation necrosis in brain metastasis patients treated with stereotactic radiosurgery and immunotherapy. Clin Neurol Neurosurg (2019) 179:14-8. doi: 10.1016/ j.clineuro.2019.02.010

10. Soussain C, Ricard D, Fike JR, Mazeron JJ, Psimaras D, Delattre JY. CNS complications of radiotherapy and chemotherapy. Lancet (London England) (2009) 374(9701):1639-51. doi: 10.1016/s0140-6736(09)61299-x

11. Jiang X, Engelbach JA, Yuan L, Cates J, Gao F, Drzymala RE, et al. Anti-VEGF antibodies mitigate the development of radiation necrosis in mouse brain. Clin Cancer Res (2014) 20(10):2695-702. doi: 10.1158/1078-0432.ccr-13-1941

12. Wong ET, Huberman M, Lu X-Q, Mahadevan A. Bevacizumab reverses cerebral radiation necrosis. J Clin Oncol Off J Am Soc Clin Oncol (2008) 26 (34):5649-50. doi: 10.1200/jco.2008.19.1866

13. Remon J, Le Pechoux C, Caramella C, Dhermain F, Louvel G, Soria JC, et al. Brain Radionecrosis Treated with Bevacizumab in a Patient with Resected Squamous Cell Carcinoma of the Lung. J Thoracic Oncol Off Publ Int Assoc Study Lung Cancer (2017) 12(1):e1-3. doi: 10.1016/j.jtho.2016.08.124

14. Jeyaretna DS, Curry WTJr., Batchelor TT, Stemmer-Rachamimov A, Plotkin SR. Exacerbation of cerebral radiation necrosis by bevacizumab. J Clin Oncol Off J Am Soc Clin Oncol (2011) 29(7):e159-62. doi: 10.1200/jco.2010.31.4815

15. Tye K, Engelhard HH, Slavin KV, Nicholas MK, Chmura SJ, Kwok Y, et al. An analysis of radiation necrosis of the central nervous system treated with bevacizumab. J Neurooncol (2014) 117(2):321-7. doi: 10.1007/s11060-0141391-8

16. Benoit A, Ducray F, Cartalat-Carel S, Psimaras D, Ricard D, Honnorat J. Favorable outcome with bevacizumab after poor outcome with steroids in a patient with temporal lobe and brainstem radiation necrosis. J Neurol (2011) 258(2):328-9. doi: 10.1007/s00415-010-5747-5

17. Arratibel-Echarren I, Albright K, Dalmau J, Rosenfeld MR. Use of Bevacizumab for neurological complications during initial treatment of malignant gliomas. Neurologia (2011) 26(2):74-80. doi: 10.1016/ j.nrl.2010.05.010

18. Alessandretti M, Buzaid AC, Brandão R, Brandão EP. Low-dose bevacizumab is effective in radiation-induced necrosis. Case Rep Oncol (2013) 6(3):598-601. doi: 10.1159/000357401

19. Xiang-Pan L, Yuxin C, Xiao-Fei W, Na L, Tang-Peng X, Xiao-Tao X, et al. Bevacizumab alleviates radiation-induced brain necrosis: A report of four cases. J Cancer Res Ther (2015) 11(2):485-7. doi: 10.4103/0973-1482.140782
20. Stroup DF, Berlin JA, Morton SC, Olkin I, Williamson GD, Rennie D, et al. Meta-analysis of Observational Studies in EpidemiologyA Proposal for Reporting. Jama (2000) 283(15):2008-12. doi: 10.1001/jama.283.15.2008

21. Higgins JPT, Altman DG, Gøtzsche PC, Jüni P, Moher D, Oxman AD, et al. The Cochrane Collaboration's tool for assessing risk of bias in randomised trials. BMJ (2011) 343:d5928. doi: 10.1136/bmj.d5928

22. Gonzalez J, Kumar AJ, Conrad CA, Levin VA. Effect of bevacizumab on radiation necrosis of the brain. Int J Radiat Oncol Biol Physics (2007) 67 (2):323-6. doi: 10.1016/j.ijrobp.2006.10.010

23. Torcuator R, Zuniga R, Mohan YS, Rock J, Doyle T, Anderson J, et al. Initial experience with bevacizumab treatment for biopsy confirmed cerebral radiation necrosis. J Neurooncol (2009) 94(1):63-8. doi: 10.1007/s11060009-9801-z

24. Levin VA, Bidaut L, Hou P, Kumar AJ, Wefel JS, Bekele BN, et al. Randomized double-blind placebo-controlled trial of bevacizumab therapy for radiation necrosis of the central nervous system. Int J Radiat Oncol Biol Physics (2011) 79(5):1487-95. doi: 10.1016/j.ijrobp.2009.12.061

25. Wang Y, Pan L, Sheng X, Mao Y, Yao Y, Wang E, et al. Reversal of cerebral radiation necrosis with bevacizumab treatment in 17 Chinese patients. European. J Med Res (2012) 17(1):25. doi: 10.1186/2047-783X-17-25

26. Boothe D, Young R, Yamada Y, Prager A, Chan T, Beal K. Bevacizumab as a treatment for radiation necrosis of brain metastases post stereotactic radiosurgery. Neuro Oncol (2013) 15(9):1257-63. doi: 10.1093/neuonc/not085

27. Furuse M, Nonoguchi N, Kawabata S, Yoritsune E, Takahashi M, Inomata T, et al. Bevacizumab Treatment for Symptomatic Radiation Necrosis Diagnosed by Amino Acid PET. Japanese J Clin Oncol (2013) 43(3):337-41. doi: 10.1093/ jjco/hys231

28. Yonezawa S, Miwa K, Shinoda J, Nomura Y, Asano Y, Nakayama N, et al. Bevacizumab treatment leads to observable morphological and metabolic changes in brain radiation necrosis. J Neurooncol (2014) 119(1):101-9. doi: 10.1007/s11060-014-1453-y

29. Sadraei NH, Dahiya S, Chao ST, Murphy ES, Osei-Boateng K, Xie H, et al. Treatment of cerebral radiation necrosis with bevacizumab: the Cleveland clinic experience. Am J Clin Oncol (2015) 38(3):304-10. doi: 10.1097/ COC.0b013e31829c3139

30. Zhuang H, Yuan X, Zheng Y, Li X, Chang JY, Wang J, et al. A study on the evaluation method and recent clinical efficacy of bevacizumab on the treatment of radiation cerebral necrosis. Sci Rep (2016) 6:24364doi: $10.1038 /$ srep24364

31. Li Y, Huang X, Jiang J, Hu W, Hu J, Cai J, et al. Clinical Variables for Prediction of the Therapeutic Effects of Bevacizumab Monotherapy in Nasopharyngeal Carcinoma Patients With Radiation-Induced Brain Necrosis. Int J Radiat Oncol Biol Physics (2018) 100(3):621-9. doi: 10.1016/ j.ijrobp.2017.11.023

32. Xu Y, Rong X, Hu W, Huang X, Li Y, Zheng D, et al. Bevacizumab Monotherapy Reduces Radiation-induced Brain Necrosis in Nasopharyngeal Carcinoma Patients: A Randomized Controlled Trial. Int J Radiat Oncol Biol Physics (2018) 101(5):1087-95. doi: 10.1016/ j.ijrobp.2018.04.068

33. Zhuang H, Zhuang H, Shi S, Wang Y. Ultra-Low-Dose Bevacizumab For Cerebral Radiation Necrosis: A Prospective Phase II Clinical Study. OncoTarg Ther (2019) 12:8447-53. doi: 10.2147/OTT.S223258

34. Blonigen BJ, Steinmetz RD, Levin L, Lamba MA, Warnick RE, Breneman JC. Irradiated volume as a predictor of brain radionecrosis after linear accelerator stereotactic radiosurgery. Int J Radiat Oncol Biol Physics (2010) 77(4):9961001. doi: 10.1016/j.ijrobp.2009.06.006

35. Chung $\mathrm{C}$, Bryant A, Brown PD. Interventions for the treatment of brain radionecrosis after radiotherapy or radiosurgery. Cochrane Database Systematic Rev (2018) 7(7):Cd011492. doi: 10.1002/14651858.CD011492.pub2

36. Miller JA, Bennett EE, Xiao R, Kotecha R, Chao ST, Vogelbaum MA, et al. Association Between Radiation Necrosis and Tumor Biology After Stereotactic Radiosurgery for Brain Metastasis. Int J Radiat Oncol Biol Physics (2016) 96(5):1060-9. doi: 10.1016/j.ijrobp.2016.08.039

37. Rahmathulla G, Marko NF, Weil RJ. Cerebral radiation necrosis: a review of the pathobiology, diagnosis and management considerations. J Clin Neurosci (2013) 20(4):485-502. doi: 10.1016/j.jocn.2012.09.011

38. Ali FS, Arevalo O, Zorofchian S, Patrizz A, Riascos R, Tandon N, et al. Cerebral Radiation Necrosis: Incidence, Pathogenesis, Diagnostic Challenges, 
and Future Opportunities. Curr Oncol Rep (2019) 21(8):66. doi: 10.1007/ s11912-019-0818-y

39. Vellayappan B, Tan CL, Yong C, Khor LK, Koh WY, Yeo TT, et al. Diagnosis and Management of Radiation Necrosis in Patients With Brain Metastases. Front Oncol (2018) 8:395. doi: 10.3389/fonc.2018.00395

40. Colaco RJ, Martin P, Kluger HM, Yu JB, Chiang VL. Does immunotherapy increase the rate of radiation necrosis after radiosurgical treatment of brain metastases? J Neurosurg (2016) 125(1):17-23. doi: 10.3171/2015.6.Jns142763

41. Levin VA, Yung WK, Bruner J, Kyritsis A, Leeds N, Gleason MJ, et al. Phase II study of accelerated fractionation radiation therapy with carboplatin followed by PCV chemotherapy for the treatment of anaplastic gliomas. Int J Radiat Oncol Biol Physics (2002) 53(1):58-66. doi: 10.1016/s0360-3016 (01)02819-x

42. Mayer R, Sminia P. Reirradiation tolerance of the human brain. Int J Radiat Oncol Biol Physics (2008) 70(5):1350-60. doi: 10.1016/j.ijrobp.2007.08.015

43. Chin LS, Ma L, DiBiase S. Radiation necrosis following gamma knife surgery: a case-controlled comparison of treatment parameters and long-term clinical follow up. J Neurosurg (2001) 94(6):899-904. doi: 10.3171/jns.2001.94.6.0899

44. Minniti G, Clarke E, Lanzetta G, Osti MF, Trasimeni G, Bozzao A, et al. Stereotactic radiosurgery for brain metastases: analysis of outcome and risk of brain radionecrosis. Radiat Oncol (London England) (2011) 6:48. doi: 10.1186/ $1748-717 \mathrm{x}-6-48$

45. Kohutek ZA, Yamada Y, Chan TA, Brennan CW, Tabar V, Gutin PH, et al. Long-term risk of radionecrosis and imaging changes after stereotactic radiosurgery for brain metastases. J Neurooncol (2015) 125(1):149-56. doi: 10.1007/s11060-015-1881-3

46. Shaw E, Scott C, Souhami L, Dinapoli R, Kline R, Loeffler J, et al. Single dose radiosurgical treatment of recurrent previously irradiated primary brain tumors and brain metastases: final report of RTOG protocol 90-05. Int $J$ Radiat Oncol Biol Physics (2000) 47(2):291-8. doi: 10.1016/s0360-3016(99) 00507-6

47. Shaw PJ, Bates D. Conservative treatment of delayed cerebral radiation necrosis. J Neurol Neurosurg Psychiatry (1984) 47(12):1338-41. doi: 10.1136/ jnnp.47.12.1338

48. Johannesen TB, Lien HH, Hole KH, Lote K. Radiological and clinical assessment of long-term brain tumour survivors after radiotherapy. Radiother Oncol J Eur Soc Ther Radiol Oncol (2003) 69(2):169-76. doi: 10.1016/s0167-8140(03)00192-0

49. Kohshi K, Imada H, Nomoto S, Yamaguchi R, Abe H, Yamamoto H. Successful treatment of radiation-induced brain necrosis by hyperbaric oxygen therapy. J Neurol Sci (2003) 209(1-2):115-7. doi: 10.1016/s0022510x (03)00007-8

50. Leber KA, Eder HG, Kovac H, Anegg U, Pendl G. Treatment of Cerebral Radionecrosis by Hyperbaric Oxygen Therapy. Stereotactic Funct Neurosurg (1998) 70(suppl 1):229-36. doi: 10.1159/000056426

51. Ohguri T, Imada H, Kohshi K, Kakeda S, Ohnari N, Morioka T, et al. Effect of prophylactic hyperbaric oxygen treatment for radiation-induced brain injury after stereotactic radiosurgery of brain metastases. Int J Radiat Oncol Biol Physics (2007) 67(1):248-55. doi: 10.1016/j.ijrobp.2006.08.009

52. Xing S, Fan Z, Shi L, Yang Z, Bai Y. Successful treatment of brain radiation necrosis resulting from triple-negative breast cancer with Endostar and shortterm hyperbaric oxygen therapy: a case report. OncoTarg Ther (2019) 12:2729-35. doi: 10.2147/OTT.S190409

53. Mou YG, Sai K, Wang ZN, Zhang XH, Lu YC, Wei DN, et al. Surgical management of radiation-induced temporal lobe necrosis in patients with nasopharyngeal carcinoma: report of 14 cases. Head Neck (2011) 33(10):1493500. doi: 10.1002/hed.21639

54. McPherson CM, Warnick RE. Results of contemporary surgical management of radiation necrosis using frameless stereotaxis and intraoperative magnetic resonance imaging. J Neurooncol (2004) 68(1):41-7. doi: 10.1023/b: neon.0000024744.16031.e9

55. Zhuang H, Shi S, Yuan Z, Chang JY. Bevacizumab treatment for radiation brain necrosis: mechanism, efficacy and issues. Mol Cancer (2019) 18(1):21. doi: 10.1186/s12943-019-0950-1

56. Rahmathulla G, Recinos PF, Valerio JE, Chao S, Barnett GH. Laser Interstitial Thermal Therapy for Focal Cerebral Radiation Necrosis: A Case Report and Literature Review. Stereotactic Funct Neurosurg (2012) 90(3):192-200. doi: $10.1159 / 000338251$
57. Hong CS, Deng D, Vera A, Chiang VL. Laser-interstitial thermal therapy compared to craniotomy for treatment of radiation necrosis or recurrent tumor in brain metastases failing radiosurgery. J Neurooncol (2019) 142 (2):309-17. doi: 10.1007/s11060-019-03097-z

58. Ahluwalia M, Barnett GH, Deng D, Tatter SB, Laxton AW, Mohammadi AM, et al. Laser ablation after stereotactic radiosurgery: a multicenter prospective study in patients with metastatic brain tumors and radiation necrosis. J Neurosurg (2018) 130(3):804-11. doi: 10.3171/2017.11.Jns171273

59. Tanigawa K, Mizuno K, Kamenohara Y, Unoki T, Misono S, Inoue H. Effect of bevacizumab on brain radiation necrosis in anaplastic lymphoma kinasepositive lung cancer. Respirol Case Rep (2019) 7(7):e00454. doi: 10.1002/ rcr2.454

60. Sanborn MR, Danish SF, Rosenfeld MR, O’Rourke D, Lee JY. Treatment of steroid refractory, Gamma Knife related radiation necrosis with bevacizumab: case report and review of the literature. Clin Neurol Neurosurg (2011) 113 (9):798-802. doi: 10.1016/j.clineuro.2011.08.007

61. Tripathi M, Ahuja CK, Mukherjee KK, Kumar N, Dhandapani S, Dutta P, et al. The Safety and Efficacy of Bevacizumab for Radiosurgery - Induced Steroid - Resistant Brain Edema; Not the Last Part in the Ship of Theseus. Neurol India (2019) 67(5):1292-302. doi: 10.4103/0028-3886.271242

62. Gronier S, Bourg V, Frenay M, Cohen M, Mondot L, Thomas P, et al. [Bevacizumab for the treatment of cerebral radionecrosis]. Rev Neurol (Paris) (2011) 167(4):331-6. doi: 10.1016/j.neurol.2010.10.012

63. Jain RK. Normalization of tumor vasculature: an emerging concept in antiangiogenic therapy. Sci (N Y NY) (2005) 307(5706):58-62. doi: 10.1126/ science. 1104819

64. Delishaj D, Ursino S, Pasqualetti F, Cristaudo A, Cosottini M, Fabrini MG, et al. Bevacizumab for the Treatment of Radiation-Induced Cerebral Necrosis: A Systematic Review of the Literature. J Clin Med Res (2017) 9(4):273-80. doi: 10.14740 /jocmr2936e

65. Miyatake S-I, Nonoguchi N, Furuse M, Yoritsune E, Miyata T, Kawabata S, et al. Pathophysiology, diagnosis, and treatment of radiation necrosis in the brain. Neurol Med Chir (Tokyo) (2015) 55(1):50-9. doi: 10.2176/nmc.ra.20140188

66. Parvez K, Parvez A, Zadeh G. The diagnosis and treatment of pseudoprogression, radiation necrosis and brain tumor recurrence. Int $J$ Mol Sci (2014) 15(7):11832-46. doi: 10.3390/ijms150711832

67. Shah R, Vattoth S, Jacob R, Manzil FFP, O’Malley JP, Borghei P, et al. Radiation Necrosis in the Brain: Imaging Features and Differentiation from Tumor Recurrence. RadioGraphics (2012) 32(5):1343-59. doi: 10.1148/ rg. 325125002

68. Chernov MF, Hayashi M, Izawa M, Usukura M, Yoshida S, Ono Y, et al. Multivoxel proton MRS for differentiation of radiation-induced necrosis and tumor recurrence after gamma knife radiosurgery for brain metastases. Brain Tumor Pathol (2006) 23(1):19-27. doi: 10.1007/s10014-006-0194-9

69. Furuuchi K, Nishiyama A, Yoshioka H, Yokoyama T, Ishida T. Reenlargement of radiation necrosis after stereotactic radiotherapy for brain metastasis from lung cancer during bevacizumab treatment. Respir Investig (2017) 55(2):1847. doi: 10.1016/j.resinv.2016.11.001

70. Kim JH, Chung YG, Kim CY, Kim HK, Lee HK. Upregulation of VEGF and FGF2 in normal rat brain after experimental intraoperative radiation therapy. J Korean Med Sci (2004) 19(6):879-86. doi: 10.3346/jkms.2004.19.6.879

71. Wong ET, Brem S. Antiangiogenesis treatment for glioblastoma multiforme: challenges and opportunities. J Natl Compr Cancer Netw JNCCN (2008) 6 (5):515-22. doi: 10.6004/jnccn.2008.0039

72. Sedgwick P. Retrospective cohort studies: advantages and disadvantages. $B M J$ Br Med J (2014) 348:g1072. doi: 10.1136/bmj.g1072

Conflict of Interest: The authors declare that the research was conducted in the absence of any commercial or financial relationships that could be construed as a potential conflict of interest.

Copyright $\odot 2021$ Liao, Khan, Zhao, Arooj, Yan and Li. This is an open-access article distributed under the terms of the Creative Commons Attribution License (CC BY). The use, distribution or reproduction in other forums is permitted, provided the original author(s) and the copyright owner(s) are credited and that the original publication in this journal is cited, in accordance with accepted academic practice. No use, distribution or reproduction is permitted which does not comply with these terms. 